\title{
Polycyclic aromatic hydrocarbons and polychlorinated biphenyls in sewage sludge from wastewater treatment plants of Kunming City
}

\author{
XiaomingLi, Shimin Zhao, Shigang Li \\ Kunming Environmental Monitoring Center \\ Kunming, Yunnan, China \\ lixiaoming.km@163.com
}

\begin{abstract}
In this study, the concentrations, distribution and sources of 16 polycyclic aromatic hydrocarbons (PAHs) and 28 polychlorinated biphenyls (PCBs) insewage sludge samples from wastewater treatment plants of Kunming citywere investigated. The total PAHs concentration (इPAHs) varied from 1941

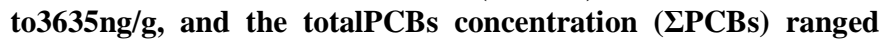
from 7.55 to $21.66 \mathrm{ng} / \mathrm{g}$. The results of sources identification suggested that PAHs in sewage sludge were mostlyproduced from biomass and petroleum combustion. PCBs compositionand congener ratios indicated that the less chlorinated were the dominant source.
\end{abstract}

Keywords- Polycyclic aromatic hydrocarbons; Polychlorinated biphenyls; Sewage sludge; Wastewater treatment plants

\section{INTRODUCTION}

Polycyclic aromatic hydrocarbons (PAHs) and polychlorinated biphenyls (PCBs) are two kinds of typical persistent organic pollutants (POPs) for their toxicity, bioaccumulation, persistence, and impact on both ecosystems and human health. Generally, PAHs and PCBs are widely distributed in the environment and can be found in every corner of our lives ${ }^{[1-2]}$.

For their lipophilic and hydrophobic properties, sedimentsare the primary environmental repository of PAHs and $\mathrm{PCBs}^{[3-4]}$. So they notably adsorb onto particulate after entering the treatment works. And then, theywill be removed during the primary and secondary sedimentation of the wastewaters and subsequently transferred to the sludge ${ }^{[5-}$ ${ }^{7]}$.However, when sludge is used as fertilizer or disposed of in landfills, PAHs and PCBs will contaminate soil. Therefore, sludge should be monitored to prevent pollution ${ }^{[8]}$. In this study, the concentrations, distribution and source of PAHs and PCBs were discussed insewage sludge samples collected from wastewater treatment plants (WWTPs) of Kunming city. Operational conditionsof the WWTPs are shown in Table I .

\section{MATERIALS AND METHODS}

\section{A. Materials}

In this study, 16 PAHs (mixture standard solution: 2000 $\mu \mathrm{g} / \mathrm{mL}$, Supelco, USA) and 28 PCBs (mixture standard solution: $100 \mu \mathrm{g} / \mathrm{mL}$, Accustandard, USA) were analyzed. For PAHs, they included 2-ring PAHs (naphthalene, Na), 3-ring

\author{
Shimin Zhao, Xiaoxia Yang,Daowei Wang, Shigang Li, \\ Xuejun Pan \\ Faculty ofEnvironmental Science and Engineering, Kunming \\ University of Science and Technology \\ Kunming, Yunnan, China \\ xjpan@kmust.edu.cn
}

PAHs (acenaphthylene, Acy; acenaphthene, Ace; fluorine, Flu; anthracene, An; phenanthrene, Ph) , 4-ring PAHs (fluoranthene, Fl; pyrene, Pyr; benzo[a]anthracene, BaA; chrysene, Chrys), 5-ring PAHs (benzo[b]fluoranthene, BbF; benzo[k]fluoranthene, $\mathrm{BkF}$; benzo[a]pyrene, $\mathrm{BaP}$; dibenzo[a,h]anthracene, dBanA) and 6-ring PAHs (indeno[1,2,3-c,d]pyrene, IP; benzo[g,h,i]perylene, BghiP). For PCBs, there aredi-chlorinated homologs(CB8), trichlorinated homologs(CB18, CB28), tetra-chlorinated homologs(CB44, CB52, CB66, CB77, CB81), pentachlorinated homologs(CB101, CB105, CB114, CB118, CB123, CB126)hexa-chlorinated homologs(CB128, CB138, CB153, CB156, CB157, CB167, CB169), hepta-chlorinated homologs (CB170, CB180, CB187, CB189), ocatachlorinated homologs(CB195), nona-chlorinated homologs (CB206), deca-chlorinated homologs (CB209).

\section{B. Sampling and Sampling Treatment}

Sampling campaign of the sewage sludge was carried out in June2012. Samples from each sampling sitewerewell mixed and stored in $1 \mathrm{~L}$ brown bottles thatwereheated at $400^{\circ} \mathrm{C}$ for 6 $\mathrm{h}$ in a muffle furnace before sampling. Each sample was frozen at $-20^{\circ} \mathrm{C}$ on the day of collection. Before analysis, all samples were dried in vacuum freeze drier at less than $-40^{\circ} \mathrm{C}$ for $48 \mathrm{~h}$. Then all freeze-dried samples were passed through a 100 mesh sieveand put into $100 \mathrm{~mL}$ brown bottles for analysis.

\section{Analytical Methods}

The procedures of sample extraction and analysis were performed according to previously reported methods by Wang ${ }^{[9]}$.

Samples were extracted by accelerated solvent extraction (ASE). A weighed sample $(10.0 \mathrm{~g})$ was mixed with $2.0 \mathrm{~g}$ diatomite (pyrolyzed at $600{ }^{\circ} \mathrm{C}$ for $4 \mathrm{~h}$ ) and $2.0 \mathrm{~g}$ anhydrous sodium sulfate (pyrolyzed at $400{ }^{\circ} \mathrm{C}$ for $6 \mathrm{~h}$ ) before beingmoved into a $22 \mathrm{~mL}$ extraction cell. After that, the samples were statically extracted with a mixture of hexane/acetone $(1: 1 \quad v / v)$ using an accelerated solvent extractor (ASE-200, Dionex, USA)at 1500 psi ,90 ${ }^{\circ} \mathrm{C}$ for 6 min. Elution volume is $60 \%$ of the extraction cell. The extraction was carried out in one cycle. After removing water 
TABLE I . OPERATIONAL CONDITIONS OF WASTEWATER TREATMENTPLANTS

\begin{tabular}{|c|c|c|c|c|c|c|c|}
\hline Sites & WWTP $^{\mathbf{a}}$ & Location $^{a}$ & $\begin{array}{c}\text { Type of } \\
\text { treatment }\end{array}$ & $\begin{array}{l}\text { Sites area } \\
\left(\times 10^{3} \mathbf{m}^{2}\right)\end{array}$ & $\begin{array}{l}\text { Population } \\
\left(\times 10^{3}\right)\end{array}$ & $\begin{array}{c}\text { Flow } \\
\left(\times 10^{3} \mathrm{~m}^{3} / \mathrm{d}\right)\end{array}$ & $\begin{array}{c}\text { Received wastewater } \\
\text { area }\left(\mathrm{Km}^{2}\right)\end{array}$ \\
\hline S1 & The first WWTP & Urban southern & Oxidation ditch & 114 & 30 & 12 & 24 \\
\hline S2 & The second WWTP & Urban southeast & Improved $\mathrm{A}^{2} / \mathrm{O}$ & 117 & 56 & 10 & 50 \\
\hline S3 & The third WWTP & Urban western & ICEAS & 121 & 55 & 21 & 42 \\
\hline $\mathrm{S} 4$ & The fourth WWTP & Urban northern & 3AMBR & 30 & 30 & 6 & 11.9 \\
\hline S5 & The fifth WWTP & Urban northern & Improved $\mathrm{A}^{2} / \mathrm{O}$ & 81 & 25.6 & 18.5 & 28.5 \\
\hline S6 & The sixth WWTP & Urban eastern & Improved $\mathrm{A}^{2} / \mathrm{O}$ & 66 & 18 & 13 & 42.4 \\
\hline S7 & The seventh and eighth WWTPs & $\begin{array}{c}\text { Urban southern, } \\
\text { eastern and } \\
\text { southeast }\end{array}$ & Improved $\mathrm{A}^{2} / \mathrm{O}$ & 210 & 57.9 & 30 & 42.3 \\
\hline
\end{tabular}

by adding $5.0 \mathrm{~g}$ anhydrous sodium sulfate, the extracts were concentrated to $2.0 \mathrm{~mL}$ bynitrogen evaporator (Turbo Vap II, Caliper, USA). For elimination of impurities, the concentrated extracts were passed through the Silica gel-Florisil composite columns activated with $7.0 \mathrm{~mL}$ hexane and flow rate 0.6 $\mathrm{mL} / \mathrm{min}$, and the target compounds were eluted with $17.0 \mathrm{~mL}$ mixture of hexane/acetone $(19: 1 v / v)$. As stated previously, the eluent was concentrated to $1.0 \mathrm{~mL}$ under a gentle stream of nitrogen for determination.

The identification and quantification of PAHs and PCBs were performed on an Agilent 7890 Gas Chromatograph coupled with Agilent 7000 GC/MS Triple Quad, Agilent 7693 Auto Sampler and DB-5 fused silica capillary column $(30 \mathrm{~m}$ $\times 0.25 \mathrm{~mm} \times 0.25 \mu \mathrm{m}) \quad$ operating in electron ionization(EI)mode. The samples were injected automatically $(1.0 \mu \mathrm{L})$ insplitless with an injection temperature of 280 ${ }^{\circ} \mathrm{C}$.And high-purity helium was used as a carrier gas (1.0 $\mathrm{mL} / \mathrm{min}$ ). The oven temperature program was as follows: initial temperature of $50{ }^{\circ} \mathrm{C}$ for $3 \mathrm{~min}$, raised at $25^{\circ} \mathrm{C} / \mathrm{min}$ to $150{ }^{\circ} \mathrm{C}$, held for $3 \mathrm{~min}$, then increased to $240{ }^{\circ} \mathrm{C}$ at $6{ }^{\circ} \mathrm{C} / \mathrm{min}$, held for $5 \mathrm{~min}$, finally to $280{ }^{\circ} \mathrm{C}$ at the rate of $16{ }^{\circ} \mathrm{C} / \mathrm{min}$, and held for $10 \mathrm{~min}$. Ion source temperature was kept at $280{ }^{\circ} \mathrm{C}$ and ions were formed under electro-ionization at $70 \mathrm{eV}$. The acquisition mode was multiple reaction monitor (MRM) with 2 parent/product ion transitions being monitored for quantification and quality analysis. Quantification of individual compounds was based on the comparison of peak areas with surrogate standards.

\section{Quality Control and Quality Assurance}

Strict quality control and assurance measures were maintained in the monitoring process. For each analytical batch of samples, reagent blanks, procedural blanks, matrix spikes, and duplicate samples were analyzed for quality control and quality assurance. None of the target compounds weredetected in the reagents, the procedural blank values was always below the detection limit.

In order to monitor the target compounds lost and defiled in the process of pretreatment and analysis, the surrogates 1,4dichlorobenzene(1,4-Dcb, Supelco, USA) and decafluorobiphenyl (Dfb, Supelco, USA) were added to the samples before extraction. The recoveries of 1,4-Dcb varied from $80.8 \%$ to $103.4 \%$ and the recoveries of Dfb varied from $92.4 \%$ to $110.8 \%$. The relative standard deviation (RSD) of sample duplicates $(n=3)$ was less than $14 \%$. The detection limits ranged from 0.001 to $0.08 \mathrm{ng} / \mathrm{g}$.

Five internal standard of PAHs (naphthalene- $\mathrm{d}_{8}$, acenaphthylene- $d_{10}$, phenanthrene- $d_{10}$, chrysene- $d_{12}$, pyrene$\left.\mathrm{d}_{12}\right)$ (Supelco, USA) and an internal standard of $\operatorname{PCBs}(2,4,5,6-$ Tetrachloro-m-xylene, Tc-m-x)(Supelco, USA) were added to all samples to monitor matrix effects. The average recoveries of internal standards of PAHs varied from $76.3 \%$ to $119.6 \%$, and the average recoveries of internal standards of PCBs varied from $94.1 \%$ to $122.9 \%$.

\section{RESULTS AND DISCUSSION}

\section{A. Concentrations of PAHs and PCBs in Sludge Samples}

The concentrations of PAHs with different ring numbersand $\Sigma \mathrm{COM} / \Sigma \mathrm{PAH}$ sin the sludge samples arelisted in Table II . The total PAH concentrations ( $\Sigma \mathrm{PAHs})$ in the sludge samples ranged from 1942 (S4) to 3635 (S3)(mean 2956) $\mathrm{ng} / \mathrm{g}$. In order of the concentrations of $\Sigma$ PAHs, the sequence was: $\mathrm{S} 3(3635 \mathrm{ng} / \mathrm{g})>\mathrm{S} 5 \quad(3456 \mathrm{ng} / \mathrm{g})>\mathrm{S} 6$ $(3342 \mathrm{ng} / \mathrm{g})>\mathrm{S} 1(3069 \mathrm{ng} / \mathrm{g})>\mathrm{S} 2(2855 \mathrm{ng} / \mathrm{g})>\mathrm{S} 7(2395 \mathrm{ng} / \mathrm{g})>$ S4 (1942ng/g). The total PAH concentrationsof municipal sludges are investigatedin other studies. For example, Zeng found that the total 15 PAHs varied from 682.6 to $6926.6 \mathrm{ng} / \mathrm{g}$ in sludge from 6 WWTPs in Guangdong ${ }^{[8]}$. Fang found that the total 16 PAHs ranged from 1156 to $6803 \mathrm{ng} \mathrm{g}^{-1}$ in sludge from 14 WWTPs in Shanghai ${ }^{[10]}$. Dai detected 2467.31$25923.79 \mathrm{ng} / \mathrm{g}$ PAHs in six sewage sludges collected in Beijing from 2004 to $2005^{[11]}$. Perez found 3940 and 5520 ng/gPAHs in sludge from a WWTP in Spain ${ }^{[12]}$.

TABLE II . CONCENTRATIONS OF PAHsWITH DIFFERENT RING NUMBERSIN SLUDGE SAMPLES (ng/g)

\begin{tabular}{|c|c|c|c|c|c|c|c|}
\hline & \multicolumn{7}{|c|}{ Samples } \\
\hline & $S 1$ & $S 2$ & $S 3$ & $S 4$ & $S 5$ & S6 & S7 \\
\hline 2-ring & 52 & 80 & 78 & 22 & 66 & 66 & 50 \\
\hline 3-ring & 352 & 386 & 554 & 259 & 433 & 618 & 315 \\
\hline 4-ring & 1436 & 1199 & 1682 & 985 & 1706 & 891 & 917 \\
\hline 5-ring & 928 & 847 & 941 & 528 & 914 & 1046 & 749 \\
\hline 6-ring & 301 & 344 & 380 & 148 & 337 & 721 & 363 \\
\hline$\Sigma$ PAHs & 3069 & 2855 & 3635 & 1942 & 3456 & 3342 & 2395 \\
\hline $\begin{array}{l}\Sigma \mathrm{COM} \\
/ \Sigma \mathrm{PAHs} \\
\end{array}$ & 0.87 & 0.84 & 0.83 & 0.86 & 0.86 & 0.80 & 0.85 \\
\hline
\end{tabular}

The concentrations of individual congeners, di-, tri-, tetra-,penta-, hexa-, hepta-, ocata-, nona-, deca-chlorinated homologs, total PCB concentrations ( $\Sigma$ PCBs), CB170/CB28 and $\mathrm{CB} 170 / \mathrm{CB} 52$ are presented in Table III.The $\Sigma$ PCBs in 
sludge samples varied from 7.55 to $21.66 \mathrm{ng} / \mathrm{g}$, with a mean concentration of $12.22 \mathrm{ng} / \mathrm{g}$, and the order was: S6 (21.66 $\mathrm{ng} / \mathrm{g})>\mathrm{S} 5(14.68 \mathrm{ng} / \mathrm{g})>\mathrm{S} 3(11.40 \mathrm{ng} / \mathrm{g})>\mathrm{S} 2(11.23 \mathrm{ng} / \mathrm{g})>$ S7 $(9.58 \mathrm{ng} / \mathrm{g})>\mathrm{S} 1(9.42 \mathrm{ng} / \mathrm{g})>\mathrm{S} 4(7.55 \mathrm{ng} / \mathrm{g})$. Berset and Holzer (1996) observed PCB levels ranging from 43 to 550 $\mathrm{ng} / \mathrm{g}$ (as 57 ) in sewage sludge in Switzerland ${ }^{[13]}$. Blanchardobserved PCBs levels ranging from 120 to 1930 $\mathrm{ng} / \mathrm{g}$ (as $\Sigma 7)$ in sewage sludge in France ${ }^{[14]}$.

Compared with other cities, the concentrations of $\Sigma$ PAHs and $\Sigma$ PCBs insludge samples from WWTPs ofKunming Citywere relatively low. The relatively higher concentration of $\Sigma$ PAHs and $\Sigma$ PCBs was found at S3, S5 and S6,because they had a relatively higher flow value than other sites, and all of them run at full load status. The lowest concentration of $\Sigma$ PAHs and $\Sigma$ PCBs was detected at S4, which had smallest site area and the least flow value with minimum pollutant. Blanchardinvestigated PAHs and PCBs in five sewers entering the Seine Aval treatment plant in the Paris area (France). The Clichy Argenteuil sewer displayed the highest PAHs concentration in relation to its high flow value $10 \mathrm{~kg} /$ year, whose contamination level is higher than Clichy Bezons ( $8.6 \mathrm{~kg} /$ year), Reueil (3.9 kg/year), Saint Denis (2 kg for 8 months) and Nanterre (2.2 kg/year). It is also found that biodegradation process and adsorption to particles are the main elimination pathways of $\mathrm{PAHs}$ and $\mathrm{PCBs}^{[14]}$.Even though S7 had the highest flow value, S7 run at normal operation with good biodegradation process, which leaded to the pollution level of S7 was relatively lighter than other sites.

TABLEIII. CONCENTRATIONS OF PCBs IN SLUDGE SAMPLES (ng/g)

\begin{tabular}{cccccccc}
\hline & \multicolumn{7}{c}{ Samples } \\
\cline { 2 - 8 } & $\boldsymbol{S 1}$ & $\boldsymbol{S 2}$ & $\boldsymbol{S 3}$ & $\boldsymbol{S 4}$ & $\boldsymbol{S 5}$ & $\boldsymbol{S 6}$ & $\boldsymbol{S 7}$ \\
\hline Di-PCBs & 0.16 & 0.17 & 0.14 & 0.11 & 0.2 & 0.21 & 0.15 \\
Tri-PCBs & 1.82 & 2.13 & 2.27 & 1.06 & 4.44 & 1.72 & 1.19 \\
Tetra-PCBs & 4.03 & 5.15 & 4.89 & 3.99 & 7.15 & 10.06 & 4.94 \\
Penta-PCBs & 0.86 & 0.79 & 0.67 & 0.65 & 0.69 & 0.71 & 0.77 \\
Hexa-PCBs & 2.16 & 2.1 & 2.01 & 1.37 & 1.49 & 1.69 & 1.85 \\
Hepta-PCBs & 0.39 & 0.32 & 0.23 & 0.29 & 0.25 & 0.39 & 0.37 \\
Ocata-PCBs & ND & ND & ND & ND & ND & ND & ND \\
Nona-PCBs & ND & ND & 0.03 & ND & ND & 0.09 & ND \\
Deca-PCBs & ND & 0.57 & 1.16 & 0.08 & 0.46 & 6.79 & 0.31 \\
IPCBs & 9.42 & 11.23 & 11.4 & 7.55 & 14.68 & 21.66 & 9.58 \\
CB170/CB28 & 0.09 & 0.06 & 0.06 & 0.19 & 0.02 & 0.11 & 0.14 \\
CB170/CB52 & 0.11 & 0.07 & 0.06 & 0.12 & 0.04 & 0.05 & 0.09 \\
\hline & & & & & & \multicolumn{2}{c}{ ND: not detected }
\end{tabular}

\section{B. PAHs Composition and Sources}

The composition of PAHs in sludge ispresented in Fig.1. The 4-ring PAHs were dominant in sludge ranging from $38.31 \%$ to $50.74 \%$, except the sample from S6 where the 5-ring PAHs were dominant at $31.31 \%$. The high molecular weight PAHs ( $\geq 4$-ring) were the dominant compounds in sludge, accounting for $79.54 \%-83.84 \%$ of the $\Sigma$ PAHs, and $13.16 \%-20.46 \%$ of the $\Sigma$ PAHs were the low molecular weight PAHs (2,3-ring). The compositional pattern of PAHs by ring size in the sludge confirmed that the PAHs were dominated by combustion process. The higher ratios of combustion $\mathrm{PAH}$ species ( $\Sigma \mathrm{COMB}$; Fl, Pyr, BaA, Chrys, BbF, BkF, BaP, BghiP and IP) and $\Sigma \mathrm{PAHs}$ indicated more combustion activities. In this study, the ratios of $\Sigma \mathrm{COMB} / \Sigma \mathrm{PAHs}$ varied from 0.78 to 0.86 , which indicated that extensive combustion activities affected the PAHs in sludge samples.

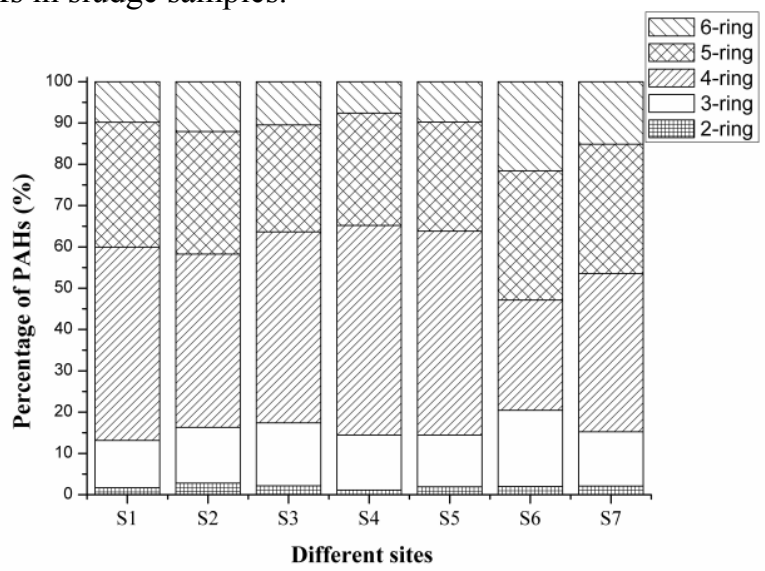

Fig.1. The distribution of PAHs with different ring numbers in different sites.

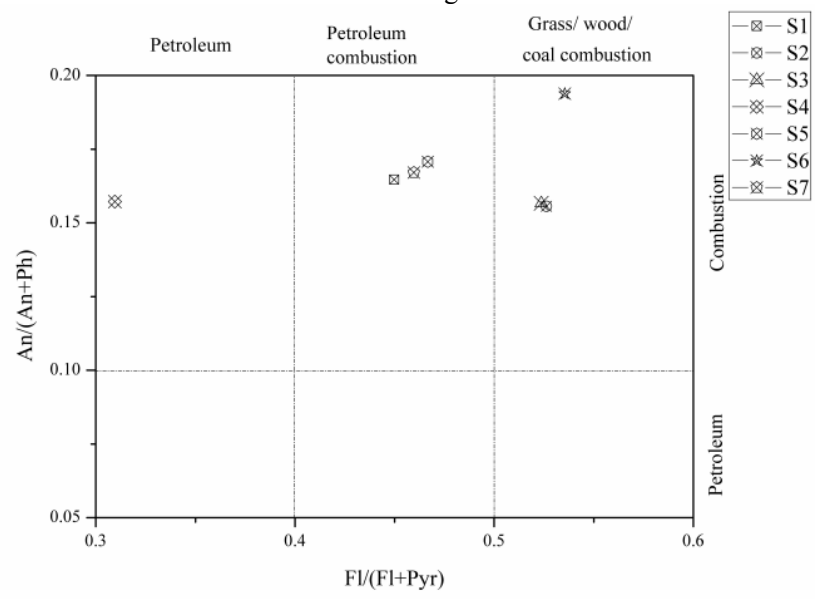

Fig.2. Plots of isomeric ratios $\mathrm{An} /(\mathrm{An}+\mathrm{Ph}) \mathrm{vs} . \mathrm{Fl} /(\mathrm{Fl}+\mathrm{Pyr})$

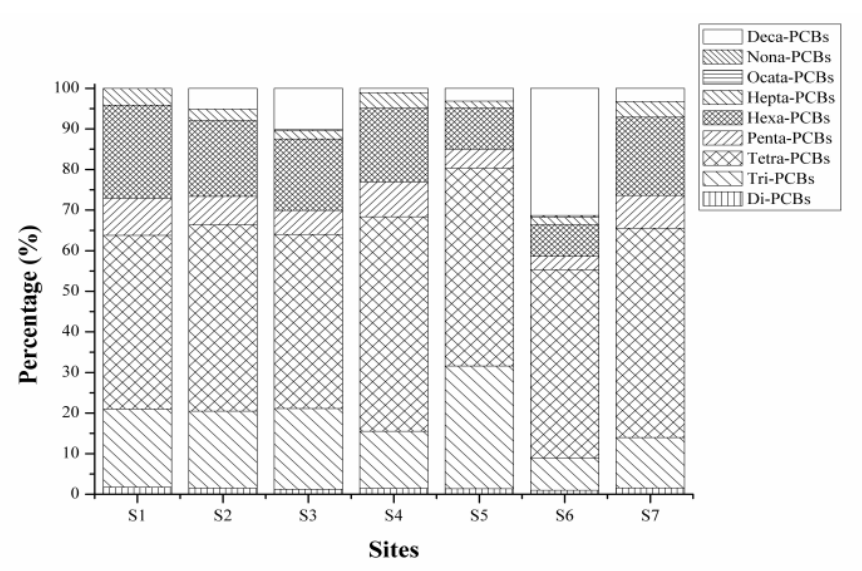

Fig. 3. Percent compositions of PCB congeners in different sites.

$\mathrm{The} \mathrm{Fl} /(\mathrm{Fl}+\mathrm{Pyr})$ versus $\mathrm{An} /(\mathrm{Ph}+\mathrm{An})$ ratios were plotted in Fig.2. In this paper, ratios of $\mathrm{An} /(\mathrm{An}+\mathrm{Ph})$ for all the sites were $>0.1$, and this means that PAHs were caused by combustion.For $\mathrm{Fl} /(\mathrm{Fl}+\mathrm{Pyr})$, the radios of some sites (S6, S3 and S2) $>0.5$ suggested that PAHs of these sites were mainly from biomass (grass, wood and coal) combustion, while the 
radios of $\mathrm{S} 4<0.4$ indicted that $\mathrm{PAHs}$ come from petroleum products. And the radios of the rest of sites (S1, S7 and S5) suggested that PAHs were mainly created by petroleum (vehicle, gasoline, fuel oil, crude oil et al.) combustion. It was similar with the primary sources of PAHs in Dianchi Lake which is the discharge area of WWTPs effluents ${ }^{[15]}$.

\section{PCBs Composition and Sources Identification}

According to the number of substituted chlorine atoms, the homologue percentages of PCBs in all samples were calculated, and areshowedin Fig.3. The tetra-PCBs were dominant congeners in all samples, followed by tri-PCBs, and hexa-PCBs (mean 47.30\%, 17.55\%, and $16.38 \%$, respectively). And the average proportions of the deca-, penta-, hepta-, di-, and nona-PCBs were $7.72 \%, 6.67 \%$, $2.89 \%, 1.40 \%$ and $0.1 \%$, respectively. Ocata-PCBs were not detected in any of the samples. Their distribution is partly indicative of the less chlorinated Aroclor mixtures such as Aroclor 1016, 1232, 1242 and 1248,whichwas consistent with previous researches on PCBs contamination in Dianchi Lake ${ }^{[1,}$ 16].

CB28, 52 and 170 belong to Tri-, Tetra- and Heptachlorine compound, respectively. Therefore, the ratio of CB170/28 and CB170/52 are usually used to assess possible sources because they are not observed in the same Aroclor mixture ${ }^{[17]}$. For all of the sites, the ratios of $\mathrm{CB} 170 / 28$ and $\mathrm{CB} 170 / 52$ varied from 0.02 to 0.19 and 0.04 to 0.12 , respectively, which suggested that the inputs were largely dominated by the less chlorinated Aroclor mixtures.

\section{CONCLUSIONS}

PAHs and PCBs in sludge from WWTPs of Kunming city were investigated and analyzed. Compared with other cities, the concentrations of $\Sigma$ PAHs and $\Sigma$ PCBs in sludgefrom WWTPs of Kunming citywere relatively low. The relatively high PAHs and PCBs concentration were observed in the WWTPs of large flowvalue (S3, S4 and S5), while the lowest concentration of $\Sigma$ PAHs and $\mathrm{PPCB}$ was detected at S4 due to the least flow value. Based on the PAH composition and isomer ratios, the possible sources of PAHs were grass, wood,coal and petroleum combustion. According to the homologue percentages of PCBs and the congener ratios, the less chlorinated were the dominant source.

\section{ACKNOWLEDGMENT}

This work was supported by National Natural Science Foundation of China (Grant No. 21267012) and National Water Pollution Control and Management Science and Technology Major Project (Grant No. 2010ZX07102-006).

\section{REFERENCES}

[1]D. H. Lin, Y. Y. Tu, and L. Z. Zhu, "Concentrations and health risk of polycyclic aromatic hydrocarbons in tea."Food Chem. Toxicol., vol. 43, pp. 41-48, January 2005.

[2]X.Wan, X.J.Pan, B.Wang, S.M.Zhao, P.Hu, F.R.Li, and B.Boulanger,"Distributions, historical trends, and source investigation of polychlorinated biphenyls in Dianchi Lake, China," Chemosphere,vol.85, pp. 361-367, October 2011.
[3] B. X. Mai, J. M. Fu, G. Zhang, Z. Lin, Y. S. Min, G. Y. Sheng, and $\mathrm{X}$. M. Wang,"Polycyclic aromatic hydrocarbons in sediments from the Pearl river and estuary, China: spatial and temporal distribution and sources," Appl. Geochem.,vol. 16, pp. 1429-1445, August-September 2001.

[4] K.T. Lee,S.Tanabe, and C.H.Koh, "Contamination of Polychlorinated Biphenyls (PCBs) in sediments from Kyeonggi Bay and Nearby Areas, Korea,"Mar. Pollut. Bull., vol. 42, pp. 273-279, April2001.

[5]B. V.Chang, S. W.Chang, and S. Y.Yuan, "Anaerobic degradation of polycyclic aromatic hydrocarbonsin sludge,"Adv. Environ. Res., vol. 7,pp. 623-628,May 2003.

[6]E.Manoli, and C.Samara, "The removal of polycyclicaromatic hydrocarbons in the wastewater treatmentprocess: Experimental calculations and model predictions,"Environ. Pollut., vol. 151, pp. 477-485, February 2008.

[7]A. J. Beck, D. L. Johnson, and K. C. Jones, "The form and bioavaibility ofnon-ionic organic chemicals in sewage sludgeamended agriculturalsoils," Sci. Tot. Environ.,vol. 185, pp. 125149, June1996.

[8]X. Y. Zeng, Z. Lin, H. Y. Gui, W. L. Shao, G. Y. Sheng, J. M. Fu, and Z. Q. Yu,"Occurrence and distribution of polycyclic aromatic carbons in sludges from wastewater treatment plants in Guangdong, China,” Environ. Monit. Assess.,vol.169, pp.89-100, October 2010.

[9] D.W. Wang, S.M. Zhao, W. Jin, Q.Y. Shen,P. Hu, B. Huang, and X. J. Pan,"Simultaneous Determination of 28 Polychlorinated Biphenyls and 16 Polycyclic Aromatic Hydrocarbons in Sediments Using ASE-SPE-GC-QqQ-MS/MS,"Chinese J. Anal. Chem., in press.

[10] H. L. Fang, L. Chen, X. L. Peng, X. Zhou, X. Zhou, L. Lin, and P. Nan,"Distribution characteristics of polycyclic aromatic hydrocarbons in sludge from major municipal sewage treatment plants in Shanghai,"China Acta. Pedologica. Sinica., vol. 45, pp. 1164-1169, November 2008.

[11]J. Y. Dai, M. Q. Xu,J. P. Chen, X. P. Yang, and Z. S. $\mathrm{Ke}$, "PCDD/F, PAH and heavy metals in thesewage sludge from six wastewater treatment plants inBeijing, China,"Chemosphere, vol. 66, pp.353-361, January 2007.

[12]S.Perez, M. L.Farre, M. J.Garcia, and D.Barcelo,"Occurrence of polycyclic aromatic hydrocarbons insewage sludge and their contribution to its toxicity inthe ToxAlert ${ }^{\mathbb{B}} 100$ bioassay," Chemosphere, vol. 45, pp. 705-712, November 2001.

[13]J.D.Berset, and R.Holzer, "Determination of coplanar and orthosubstituted PCBs in some sewage sludges of Switzerland usingHRGC/ECD and HRGC/MSD,"Chemosphere, vol. 32, pp. 2317-2333, June 1996.

[14]M. Blanchard, M. J. Teil, D. Ollivon, L. Legenti, and M. Chevreuil, "Polycyclic aromatic hydrocarbons and polychlorobiphenyls in wastewaters and sewage sludges from the Paris area (France),"Environ. Res., vol. 95,pp.184-197, June 2004.

[15] S. M. Zhao, D. W. Wang, B. Wang, X. M. Li, B. Huang, P. Hu, L. W. Zhang and X. J. Pan, "Distributions, Sources and Risk Assessment of Polycyclic Aromatic Hydrocarbons in Surface Sediments from Dianchi Lake, China," unpublished.

[16] S. M. Zhao, D. W. Wang, X. M. Li, Z. Y. Li, B. Wang, X. Wan, B. Huang, and X. J. Pan, "Polychlorinated Biphenyls in Surface Sediments ofDianchi Lake, China," unpublished. 
[17] P. C. Hartmann, J. G. Quinn, R. W. Cairns, and J. W. King, "Polychlorinated biphenyls in Narragansett Bay surface sediment,"Chemosphere,vol.57, pp. 9-20, October 2004. 